\title{
Modelos de policía. Hacia un modelo de seguridad plural, de F. Guillén. Barcelona: J.M. Bosch Editor, 2016
}

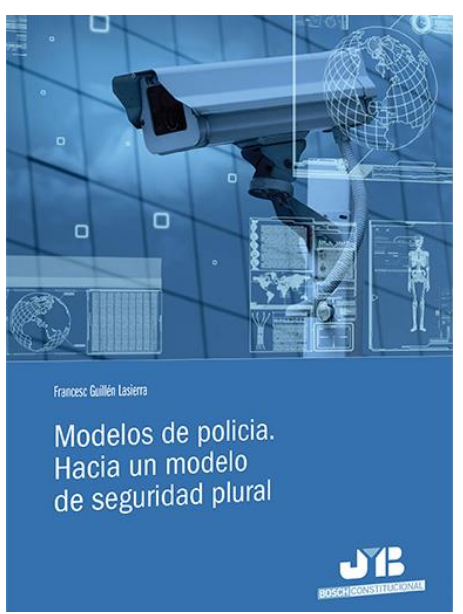

\section{JOSÉ E. MEDINA SARMIENTO}

Investigador del Centro Crímina para el estudio y prevención de la delincuencia de la Universidad Miguel Hernández de Elche

Con el término policing los anglosajones se refieren a una suerte de estudio de la Policía, más concretamente de los diferentes aspectos de la función, la organización policial y la actividad de mantenimiento de la seguridad. Y a profundizar en el conocimiento de ésta se entregan desde la academia un buen número de científicos y desde la práctica, lo que Renee Mitchel ha denominado "pracademics". Con esta expresión, resultado de unir las palabras en lengua inglesa practitioner y academic, la Dra. Mitchel, Sargento del Departamento de Policía de Sacramento (EEUU) e investigadora del Instituto de Criminología de la Universidad de Cambridge, describe a aquellos profesionales como Francesc Guillén que, con un importante bagaje en diferentes instituciones vinculadas a la seguridad y la Policía o desde ella misma, se incorporan a universidades y centros de investigación para ahondar en el conocimiento de su profesión desde una perspectiva generalmente empírica.

$\mathrm{Y}$ es que tanto nuestros vecinos de las islas británicas, como los norteamericanos, australianos y otros muchos, han entendido que la Policía, como institución dedicada a proporcionar seguridad, debe ser estudiada desde diferentes perspectivas, también la 
científica. De este modo, han sido numerosas las investigaciones, insistimos, fundamentalmente anglosajonas, que como los trabajos de Trojanowicz y Bucqueroux se han centrado en describir las relaciones entre los agentes de la ley y la comunidad en la que prestan sus servicios. Es más, encontramos otras, como el conocido experimento de patrullaje aleatorio de Kansas City, encabezado por George Kelling, que se han dirigido a profundizar en los procedimientos policiales de vigilancia. Y más recientemente, investigadores ahora, que antes fueron policías, como Jerry Ratcliffe, han actualizado el conocimiento proporcionado por los antiguos estudios de Kansas y Seattle recurriendo a nuevas técnicas como los "mapas del crimen". En definitiva, tal es la profusión de investigaciones en lengua inglesa, que basta una simple búsqueda de revistas científicas en la base de datos Scopus introduciendo los términos "police" o "policing", para recuperar al menos quince publicaciones dedicadas en exclusiva a este tópico concreto, algunas de ellas, como "Police Quarterly" o "Policing and Society", situadas en el primer cuartil de las revistas con factor de impacto más alto.

Este interés por el estudio de la Policía no ha sido en modo alguno tan intenso en nuestro país. Razones debe haber para este pobre estado de la investigación cuyo reflejo es una limitada producción. Es posible que nuestra tardía incorporación al sistema democrático, tras años de un régimen centralista que acaparaba todas las instituciones, también la Policía, llevara a pensar que su estudio no era necesario dada su consideración de instrumento político y no de seguridad ciudadana o si se quiere pública. Puede también que, derivado de ello o no, la transición diseñase una especie de modelo, o mejor, de mapa policial, según el cual los cuerpos de policía se estructurarían a imagen y semejanza de las nuevas instituciones estatales, autonómicas y locales, provocando una indefinición que llevaría las reflexiones sobre los cuerpos de seguridad al terreno de las competencias y las distribuciones territoriales y no al de la definición de su misión, el mejor modo en que deberían desarrollar sus funciones, o a apuntalar su legitimación. Quizá, en definitiva, se deba a que la Policía pudiera ser lo que Diego Torrente definiera en "La sociedad policial. Poder, trabajo y cultura en una organización local de policía" una organización imposible, abocada a afrontar las contradicciones propias de la sociedad, sin posibilidad de ofrecer una respuesta adecuada a las demandas de parte de ella y en ciertos momentos y contextos, encerrada en sus rituales y prejuicios, sometida al "poder azul" (Torrente, 1997). 
Sea como fuere, lo cierto es que apenas unas pocas monografías en la década de los noventa, como el clásico de Barcelona Llop (1997) "Policía y Constitución” o "La profesión de policía” de Martín Fernández (1990), han indagado desde una perspectiva científica en los orígenes de la función, en sus estructuras y procesos, en su descentralización o en el modelo policial. Es por ello que la obra de Francesc Guillén "Modelos de policía: hacia un modelo de seguridad plural" ha venido a ocupar, hay que decirlo sin ninguna duda, con solvencia, un espacio hasta ahora poco transitado en lengua castellana. Por ello, resulta no solo pertinente, sino necesaria, de lectura imprescindible por la claridad con la que quien la firma, perfecto conocedor de la materia por su amplia experiencia como responsable de alto nivel en diferentes ámbitos de la seguridad y por su trayectoria investigadora y docente, desmenuza y expone los modelos y conceptos abordados. Y lo es más si consideramos que el autor no se ha limitado a una exposición de modelos policiales establecidos en la literatura precedente. Tampoco se ha conformado con realizar un relato histórico, ni con describir las funciones policiales o detallar sus estructuras, tal y como sí han hecho otras obras. Al contrario, esta publicación tiene la virtud de sistematizar los modelos policiales a partir de los elementos que los conforman y al hacerlo de este modo facilita enormemente su comprensión, descartando de este modo, aquellas aproximaciones o estrategias que, aunque tradicionalmente han sido identificadas con uno u otro modelo, no lo son por constituir en todo caso, en coherencia con la definición del objeto de estudio dada, metodologías compatibles con todos o alguno de ellos. Y es que el eje central que conduce el libro, haciendo transitar al lector por los diferentes enfoques policiales, es precisamente la discusión de los conceptos que permiten clasificar el actuar de la Policía en torno a tres grandes corrientes, la gubernativa, la profesional y la comunitaria, que devienen casi inevitablemente en la última parte de la obra en un nuevo modelo que, consecuente con lo advertido a lo largo del texto, adopta las bondades de unos y otros, huyendo de sus defectos y adaptándolo a nuevas realidades sociales, que solo podrán ser abordadas desde planteamientos como los que propone con inteligencia el autor.

Así, en el primer capítulo se muestra la evolución, funciones, particularidades y críticas del modelo gubernativo, cuya característica definitoria es su concepción como una organización que ejecuta órdenes procedentes del Gobierno con la finalidad de mantener 
el orden legítimamente establecido, con nula o muy escasa relación con la comunidad y una estructura burocrática muy potente, centralizada y jerarquizada.

A continuación, el texto nos traslada a tierras norteamericanas donde sitúa el surgimiento del segundo de los modelos estudiados, el profesional, cuyo impulsor fue August Vollmer, con el permiso de Sir Robert Peel (pág. 75 y ss.) quien inspirado en el modelo de policía japonés conocido como Kobán introdujo en la nueva Policía Metropolitana de Londres el principio de profesionalidad y la dotó de una formación adecuada. Al igual que los nuevos paradigmas científicos surgen generalmente como respuesta a las lagunas e insuficiencias de los antiguos, el modelo profesional de policía respondía, como refleja con claridad el autor por medio de numerosos ejemplos y guiado por la doctrina de Vollmer, jefe de la Policía de Berkeley y Los Angeles, a los excesos cometidos por el poder político que había convertido a los gubernativos cuerpos de policía en instituciones al servicio de la voluntad del gobernante de turno. De este modo, el modelo profesional fía su éxito a la adopción de detallados procedimientos y el cumplimiento estricto de la ley, definiendo como principal misión la lucha contra la delincuencia.

El tercer capítulo avanza, recurriendo nuevamente a Peel (pág. 121 y ss), hasta un nuevo modelo, el de policía comunitaria o policía como servicio público de seguridad, con sus variantes Policía de barrio o Policía de proximidad, concebida como un servicio público que trata de acercar al policía al resto de ciudadanos y en consecuencia, en contraposición a lo ocurrido en modelos pretéritos, incluye al policía como otro ciudadano más, que tiene como misión garantizar la seguridad de los demás. Ejemplifica en este punto el tipo de relaciones con la comunidad que se admiten en el paradigma estudiado, como el neighbourdhood watch o vigilancia comunitaria (con el que el autor es crítico), y describe profusamente los objetivos fundamentales de la Policía y los elementos que la definen según este modelo.

Tras la revisión de los modelos de policía en los tres primeros capítulos, llega para el autor el momento de analizar enfoques o aproximaciones que entiende no deben ser tenidas por modelos propiamente dichos y para ello recurre nuevamente a profundizar en las dos dimensiones que los definen. Así, desde la perspectiva de su legitimación y el estudio de sus misiones, la Policía orientada a los problemas, la Policía guiada por la inteligencia, la tolerancia cero, la Policía de aseguramiento y la de barrio no constituyen 
en modo alguno planteamientos alternativos. Todos ellos son deudores de una $\mathrm{u}$ otra característica que, en definitiva, puede identificarse con los tres modelos vistos, por lo que debe entenderse que se trata más bien de metodologías enmarcadas en ellos. Aun así, se detiene en cada uno de ellos, para siquiera destacar sus elementos principales e incidir en los puntos de contacto con el enfoque del que parten, proporcionando una imagen clara del modo en que se aplican y de su alcance.

A partir de ahí, el autor aborda la construcción de un nuevo modelo, el de "seguridad plural", y al hacerlo propone dos niveles de organización construidos sobre la base de la diferente intensidad en la especialización necesaria para desarrollar los cometidos de la policía, describiendo ordenadamente los elementos que componen la actual realidad de la seguridad, sus riesgos y amenazas, y también las oportunidades que se presentan. En este momento, corre el riesgo de desviar la atención del objeto de su estudio, ampliándolo a una revisión más general de la seguridad, pero no lo hace al situar el rol de la policía en el centro de su análisis. En torno a ella, con la ayuda de la seguridad privada, pivotarán el resto de actores, otorgando a los ciudadanos un papel relevante y activo. En este punto destaca la idea de transparencia en las intervenciones policiales y la disposición de los datos sobre seguridad (pág. 221). Sin embargo, a pesar de la publicación de leyes que promueven la apertura de los datos a fin de proporcionar información a los ciudadanos, lo cierto es que en la actualidad todavía nos encontramos lejos de alcanzar el nivel de acceso a la información anhelado por el autor. Y es que la realidad revela que el acceso a los datos oficiales sobre delincuencia es, por decirlo de algún modo, pobre, y desde luego no desciende al nivel de permitir el acceso a la información georreferenciada (pág. 222), lo que no contribuye a incrementar la auctoritas deseada. En este sentido, investigaciones como la de Julie Wartell y Tom McEwen del Crime Mapping Research Center en "Privacy in the information age", junto a otras más, han avalado la reivindicación de Francesc Guillén, al mostrar que el acceso a la información no contribuye a generar sentimientos de inseguridad, si es que esta fuera la objeción.

"Modelos de policía: hacia un modelo de seguridad plural" es, en definitiva, una magnífica obra pensada para profesionales, estudiantes e investigadores. La organización de su contenido es excelente y recoge de forma clara y comprensible los diferentes modelos de policía que han surgido y coexistido en las organizaciones policiales. Así 
analiza la legitimación y misión de cada uno de ellos, para proponer desde esta perspectiva un nuevo modelo, con caracteres distintivos, en el que se redefine el papel de sus actores, adaptado a una nueva realidad macro-micro que trasciende fronteras y también el mundo físico llevándonos al virtual, pero que no pierde la esencia geográfica de la comunidad. Y es que como Gonzalo Muinelo escribiera en "La Policía Local hoy", una de esas escasas publicaciones de los noventa a las que aludía al inicio de esta recensión, ¿va a ser ahora modificado el modelo policial español? Esta cuestión, vigente treinta años después, tendría que ser respondida con un "debería serlo", y para sentar las bases de ese cambio Francesc Guillén realiza una aportación relevante y sobre todo muy sensata, construida sobre la base de su experiencia como docente, investigador y profesional. 